\title{
Rancang Bangun Sistem Informasi Monitoring Absensi Karyawan Berbasis Website
}

\author{
Ahmad Sofyan ${ }^{1}$, Ani Oktarini Sari ${ }^{\star 2}$, Eva Zuraidah ${ }^{3}$ \\ 1,3Program Studi Sistem Informasi, Universitas Nusa Mandiri \\ 2Program Studi Sistem Informasi,Universitas Bina Sarana Informatika \\ *nioktari@gmail.com
}

\begin{abstract}
Abstrak
Absensi karyawan merupakan hal yang sangat penting sebagai penunjang yang dapat mendorong aktivitas produktifitas pekerjaan. Melakukan monitoring absensi karyawan juga memegang peranan penting dalam proses penilaian kinerja karyawan. Namun, penerapan sistem absensi karyawan pada PT Indra Karya Persada saat ini masih menggunakan buku absensi secara manual dengan menuliskan jam masuk dan jam pulang dengan tulisan tangan. Absensi yang dilakukan secara manual dapat menimbulkan masalah yang berupa data tidak sesuai, susah dalam melakukan pencarian data, dan resiko kehilangan data. selain itu, sistem absensi karyawan saat ini belum mengakomodir karyawan jika harus bertugas di luar kantor, mereka harus datang ke kantor untuk menuliskan absensinya. Untuk itulah diperlukannya sistem absensi karyawan yang terkomputerisasi dan dapat diakses dimana saja dengan koneksi internet, agar permasalahan yang ada dapat teratasi dengan baik. Dan proses monitoring dan laporan harian absensi karyawan dapat terpantau dengan baik.
\end{abstract}

Kata Kunci : monitoring absensi, Sistem Informasi, website absensi karyawan

\begin{abstract}
Employee attendance is very important as a support that can encourage work productivity activities. Monitoring employee attendance also plays an important role in the employee performance appraisal process. However, the application of the employee attendance system at PT Indra Karya Persada is currently still using the attendance book manually by writing down the hours of entry and return in handwriting. Attendance that is done manually can cause problems in the form of inappropriate data, difficulty in searching for data, and the risk of losing data. In addition, the current employee attendance system has not accommodated employees if they have to work outside the office, they must come to the office to write down their attendance. For this reason, a computerized employee attendance system that can be accessed anywhere with an internet connection is needed, so that existing problems can be resolved properly. And the process of monitoring and daily employee attendance reports can be monitored properly
\end{abstract}

Keyword : attendance monitoring, employee attendance website,Information Systems

\section{Pendahuluan}

Teknologi yang berkembang sangat cepat berpengaruh besar terhadap kehidupan manusia, teknologi komputer dan internet merupakan salah satu teknologi yang digunakan untuk mengatasi berbagai masalah baik di bidang industri, kesehatan, pendidikan dan hiburan [1]. Kebutuhan akan sistem komputerisasi juga seiring dengan berkembangnya ilmu pengetahuan dan teknologi khususnya ilmu komputer. Karena itu diketahui bersama bahwa komputer mampu mempunyai peran penting sebagai alat bantu dalam pengolahan data serta dapat memecahkan 
masalah kecil sampai dengan yang kompleks sekalipun [2]. Teknologi website kini telah banyak dimanfaatkan dan bisa dikatakan telah menjadi suatu kebutuhan penting dalam mempermudah penyampaian suatu informasi dengan cara efektif yang dapat di akses kapan saja, dimana saja dan oleh siapa saja melalui media internet dengan catatan bahwa desain website tersebut telah hosting di internet [3].

Absensi merupakan suatu hal yang penting dalam sebuah instansi perusahaan. Pencatatan absensi karyawan merupakan salah satu faktor penting dalam pengelolaan sumber daya manusia karena informasi yang mendalam dan terperinci mengenai kehadiran seorang karyawan dapat menentukan prestasi, nilai dan kemajuan instansi secara umum [4]. Jika perusahaan ingin hasil yang maksimal dan sesuai dengan tujuan yang ditetapkan maka dari itu dengan sistem absensi yang baik maka diharapkan dapat membantu dalam mengendalikan proses penyelesaian pekerjaan. Untuk dapat menghasilkan sistem informasi absensi yang terstruktur sehingga diperlukan teknologi informasi yang meliputi teknologi komputer, teknologi telekomunikasi serta teknologi apapun yang dapat memberikan nilai tambah untuk mengelola sistem tersebut [5].

PT Indra Karya Persada adalah perusahaan swasta yang bergerak dibidang Excavator dalam melakukan proses absensi saat ini menggunakan buku absensi tulis tangan. Dimana karyawan melakukan absensi dengan tulis tangan di buku absensi untuk dicatat data absensi kehadirannya. Namun, didalam situasi pandemi ini dimana protokol kesehatan yang dijalankan, tidak memungkinkan penggunaan buku absensi yang dikumpulkan bersama-sama sehingga rawan penularan. Hal ini pun menyulitkan karyawan yang bekerja diluar kantor untuk absen dan laporan harus datang ke kantor sedangkan maintenance bisa lebih dari 1 hari ditempat customer yang menyewa excavator. Pencatatan dalam buku absen tidak rapih atau tidak jelas tulisannya. Maka, dibutuhkan adanya sistem terkomputerisasi yang dapat menggantikan proses kerja pada buku absensi tersebut. Salah satunya dengan pembuatan sistem informasi monitoring absensi berbasis web. Dengan menggunakan system informasi yang terkomputerisasi maka pengguna system bisa mendapatkan informasi yang akurat secara efektif dan efisien[6]. Tujuan dalam pembuatan sistem informasi ini agar dapat mempermudah karyawan dalam melakukan absensi dan mempermudah leader dalam pemantauan monitoring absensi karyawan tersebut.

\section{Tinjauan Pustaka}

\subsection{Penelitian Terkait}

Didalam penelitian yang dilakukan oleh Vita Octa Wihanaa dan Fikri Amrullaha dengan judul 
Penerapan Sistem Informasi Presensi Mahasiswa Menggunakan Fingerprint Berbasis Web, Tujuan penelitian ini agar memudahkan mahasiswa melakukan absen dan mengantisipasi adanya kecurangan yang dilakukan mahasiswa serta admin dapat melakukan kontroling diluar area fakultas. Dilihat dari proses yang berjalan permasalahannya adalah presensi yang diterapkan di Fakultas Teknologi Informasi masih menggunakan lembar kertas yang ditanda tangani oleh setiap mahasiswa hal ini sangat tidak efisien dan membuat mahasiswa tidak disiplin. Dengan perancangan sistem yang terorganiasi berbasis web terbukti dengan menggunakan sistem berbasis web, laporan dan abensi karyawan lebih terkontrol [7].

Penelitian yang dilakukan oleh Avid Wijaya dengan judul Evaluasi Sistem Dashboard Monitoring Presensi Akademik Mahasiswa, Tujuan penelitian ini adalah untuk mengevaluasi sistem absensi yang digunakan oleh user. Dilihat dari proses yang berjalan permasalahannya adalah presensi yang diterapkan masih banyak terjadi kesalahan ketika pencatatan kehadiran. Dengan perancangan sistem yang terorganiasi ini sistem yang digunakan berdampak pada pelaksanaan monitoring kehadiran mahasiswa dalam perkuliahan. Staff administrasi dan akademik beserta mahasiswa bisa dengan cepat mengetahui informasi kehadiran yang direkap melalui aplikasi dashboard monitoring presensi [8].

\subsection{Landasan Teori}

1. Sistem

Sistem adalah jaringan yang saling berhubungan, berkumpul untuk melakukan kegiatan untuk menyelesaikan suatu tujuan tertentu [9]. Pendapat lain menurut (Muslihudin \& Oktafianto, 2016) dalam [10] Sistem adalah sebuah istilah yang secara kolektif mendeskripsikan fase-fase awal pengembangan sistem. Analisis sistem adalah teknik pemecahan masalah yang menguraikan bagian-bagian komponen tersebut bekerja dan berinteraksi untuk mencapai tujuan mereka

\section{Sistem Informasi}

Menurut Hanif Al Fattah, "Sistem informasi adalah suatu kumpulan atau himpunan dari unsur atau variabel yang saling terorganisasi, saling berinteraksi dan memiliki ketergantungan satu dengan yang lainnya [11]. Pendapat lain dari Rudy Tantra dalam[12] mengungkapkan bahwa Sistem informasi adalah cara yang terorganisir untuk mengumpulkan, memasukan, dan memproses data dan menyimpannya, mengelola, mengontrol dan melaporkannya sehingga dapat mendukung perusahaan atau organisasi untuk mencapai suatu tujuan.

3. Sistem Informasi Web

Sistem informasi berbasis web merupakan 
sistem informasi yang berbentuk website yang dalam penggunaannya memanfaatkan teknologi internet [13].

\section{Website}

Website adalah kumpulan halaman web yang memiliki sebuah domain yang mengandung informasi. Domain website adalah nama unik atau yang tidak duplikat yang dimiliki oleh sebuah institusi sehingga bisa di akses melalui internet, misalnya: ephi.id, yahoo.com, google.com dan lain-lain [14].

\section{Presensi}

Presensi pegawai dapat diartikan sebagai suatu kegiatan mencatat terhadap setiap kehadiran pegawai dengan tujuan untuk mengetahui data yang berkaitan dengan kehadiran masuk dan keluar pegawai secara periodik baik harian maupun bulanan [15]

\subsection{Tahapan Penelitian}

Adapun tahapan penelitian pengembangan perangkat lunak yang dilakukan dalam pembuatan website ini menggunakan model waterfall. Tahapan penelitian digambarkan sebagai berikut :

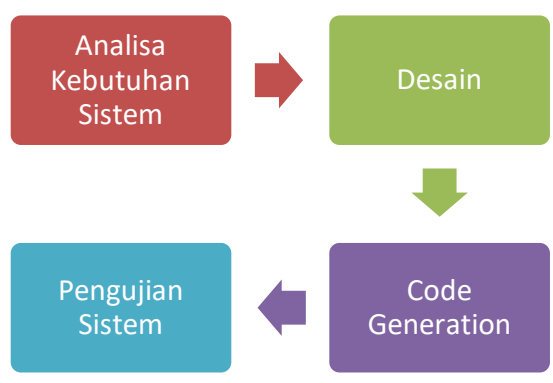

Gambar 1. Tahapan Penelitian
Penjelasan dari gambar 1 tentang tahapan penelitian :

- Analisa Kebutuhan

Menganalisa kebutuhan apa saja yang dibutuhkan dalam pembuatan sistem informasi monitoring absensi dan laporan harian karyawan berbasis web menggunakan model waterfall, diantaranya bentuk dokumen buku absensi karyawan yang akan diimplementasikan ke website.

- Desain

Melakukan perancangan sistem informasi monitoring absensi berbasis web meliputi desain sistem menggunakan UML untuk desain database menggunakan ERD.

- Code Generation

Bahasa pemrograman web yang digunakan PHP, text editor mengggunakan sublime text dan database MySQL

\section{- Pengujian Sistem}

Pada tahap ini dilakukan pengujian dari segi fungsional untuk mengecek apakah masih ada kekurangan atau kesalahan dari tahap coding. Pengujian dilakukan dengan menggunakan balckbox testing.

\section{Metode Penelitian}

\subsection{Teknik Pengumpulan Data}

Penulis melakukan pengumpulan data melalui cara: 


\section{- Observasi}

Penulis melakukan pengamatan-pengamatan langsung pada PT Indra Karya Persada. Hasil pengamatan kami langsung catat dari kegiatan observasi bagian monitoring absensi karyawan yang dapat diketahui kesalahannya dalam proses kegiatan tersebut.

- Wawancara (Interview)

Penulis menanyakan langsung kepada admin dan karyawan sehingga diperoleh penjelasan kebutuhan dari sistem monitoring absensi dan laporan karyawan yang akan dibuat untuk mempermudah perancangan sistem yang dibutuhkan.

\section{- Study Pustaka (Library Reseach)}

Selain melakukan melakukan studi kepustakaan melalui informasi dan referensi yang ada di perpusatakaan maupun di internet.

\subsection{Analisa Sistem Berjalan}

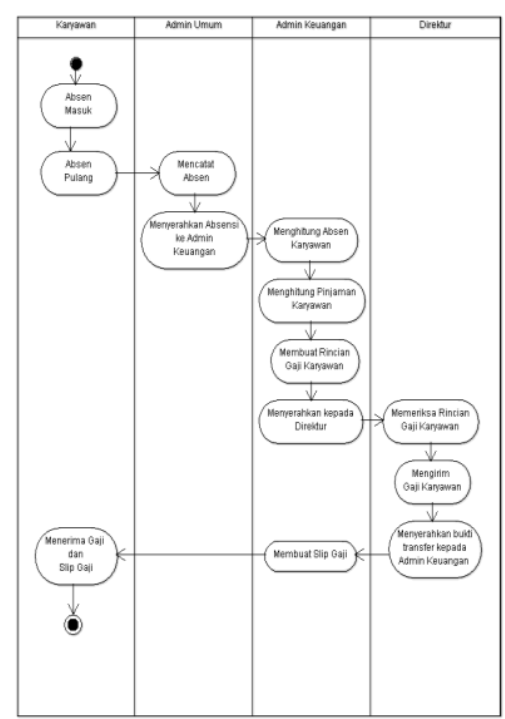

Gambar 2. Activity Diagram Sistem Berjalan

\subsection{Lokasi Penelitian}

Penelitian ini dilakukan dengan mengumpulkan sumber data yang berada di PT. Indra Karya Persada, Kelapa Gading Timur, Jakarta Utara

\section{Hasil dan Pembahasan}

a. Analisa Kebutuhan Software

Berikut ini adalah spesifikasi kebutuhan (system requrement) dari Rancang Bangun Sistem Informasi Monitoring Absensi dan Laporan Harian Karyawan berbasis website yaitu : Halaman Leader:

A1. Leader bisa login absensi berbasis web.

A2. Mengelola user password Karyawan.

A3. Menambah dan Menghapus data Karyawan

A4. Mendapat hak istimewa untuk approval absen dan laporan.

Halaman Karyawan :

B1. Karyawan bisa login absensi berbasis web.

B2. Karyawan bisa absen masuk dan keluar.

B3. Karyawan bisa lihat absensi keseluruhan.

B4. Karyawan bisa tambah catatan atau laporan untuk keperluan izin atau lembur.

B5. Karyawan bisa liat catatan keseluruhan.

b. Desain Sistem

- Use Case Diagram Leader

Dalam menjelaskan alur kerja Admin didalam sistem absensi dapat dilihat dalam gambar 3 use case diagram akses Leader 


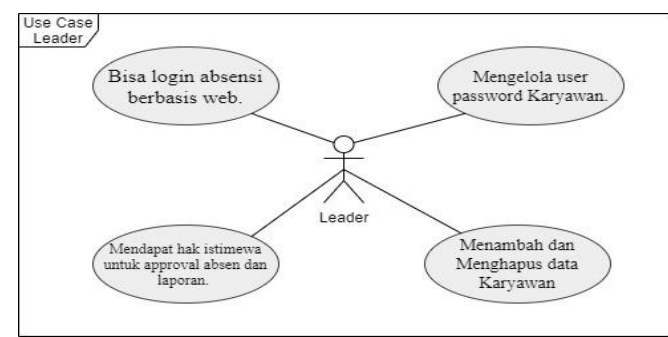

Gambar 3. Use Case Diagram Leader

Tabel 1 Deskripsi Use Case Diagram Leader

\begin{tabular}{|c|c|}
\hline Use Case Name & Login \\
\hline Goal & $\begin{array}{l}\text { Karyawan absen dan } \\
\text { laporan melalui web dan } \\
\text { Leader Monitoring melalui } \\
\text { web dengan cara } \\
\text { konfirmasi } \\
\text { karyawan }\end{array}$ \\
\hline Pre-Conditions & $\begin{array}{lr}\text { Karyawan dapat } & \text { absen } \\
\text { dan laporan di menu } \\
\text { absen dan di menu } \\
\text { catatan sebelum di } \\
\text { konfirmasi leader }\end{array}$ \\
\hline Post-Conditions & $\begin{array}{l}\text { Data absensi karyawan } \\
\text { berhasil disimpan didalam } \\
\text { database dan di konfirmasi } \\
\text { oleh leader }\end{array}$ \\
\hline $\begin{array}{l}\text { Failed } \\
\text { Condition }\end{array}$ & $\begin{array}{l}\text { Data karyawan tidak dapat } \\
\text { disimpan di database dan } \\
\text { leader tidak dapat } \\
\text { konfirmasi absen }\end{array}$ \\
\hline Actors & Leader \\
\hline $\begin{array}{l}\text { Main Flow/ } \\
\text { Basic Path }\end{array}$ & $\begin{array}{l}\text { 1. Leader bisa login } \\
\text { absensi berbasis web } \\
\text { 2. Leader Mengelola user } \\
\text { password Karyawan } \\
\text { 3. Leader Menambah dan } \\
\text { Menghapus data } \\
\text { Karyawan hak } \\
\text { 4. Leader Mendapat hak } \\
\text { istimewa untuk } \\
\text { approval absen dan } \\
\text { laporan }\end{array}$ \\
\hline
\end{tabular}

\section{- Use Case Diagram Karyawan}

Dalam menjelaskan alur kerja karyawan didalam sistem absensi dapat dilihat dalam gambar 4 use case diagram akses karyawan

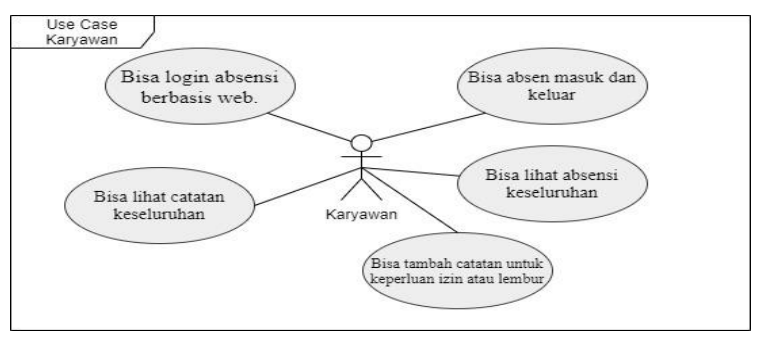

Gambar 4. Use Case Diagram Karyawan

Tabel 2 Deskripsi Use Case Diagram Karyawan

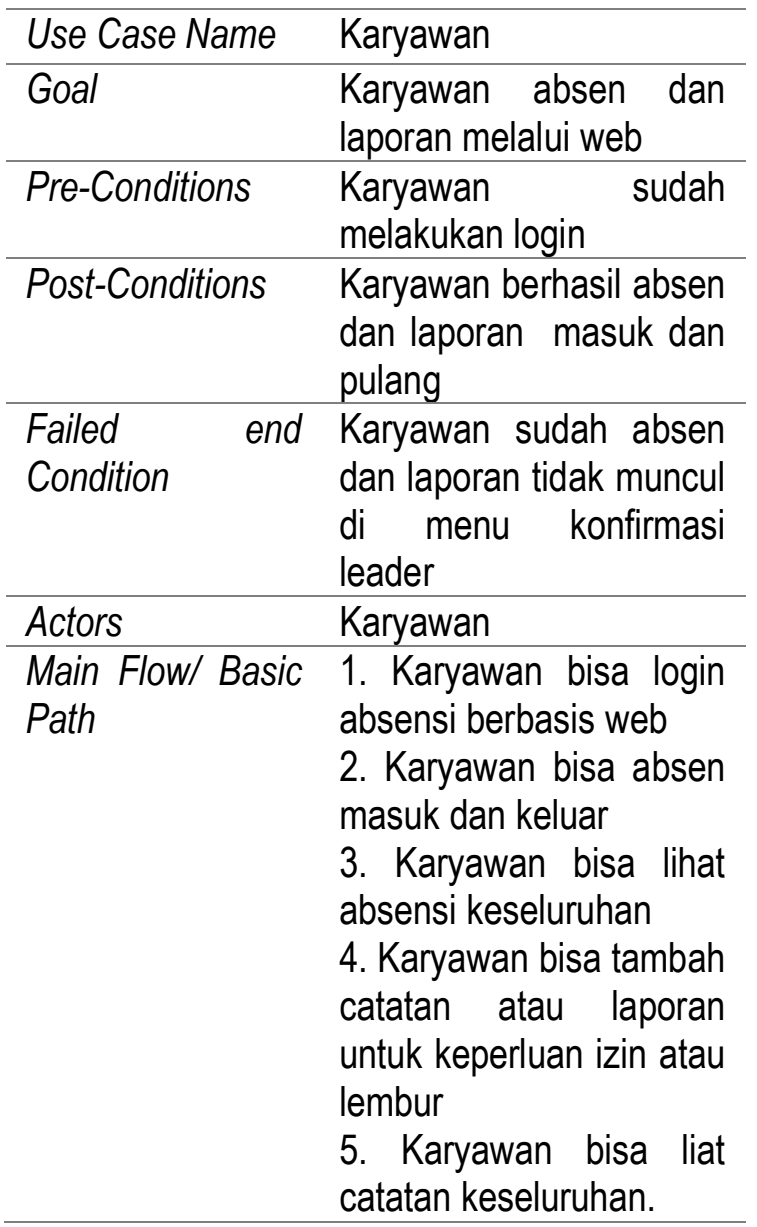


- Activity Diagram Karyawan

Dalam menjelaskan aktivitas karyawan didalam sistem absensi dapat dilihat dalam gambar 5 Activity Diagram Karyawan

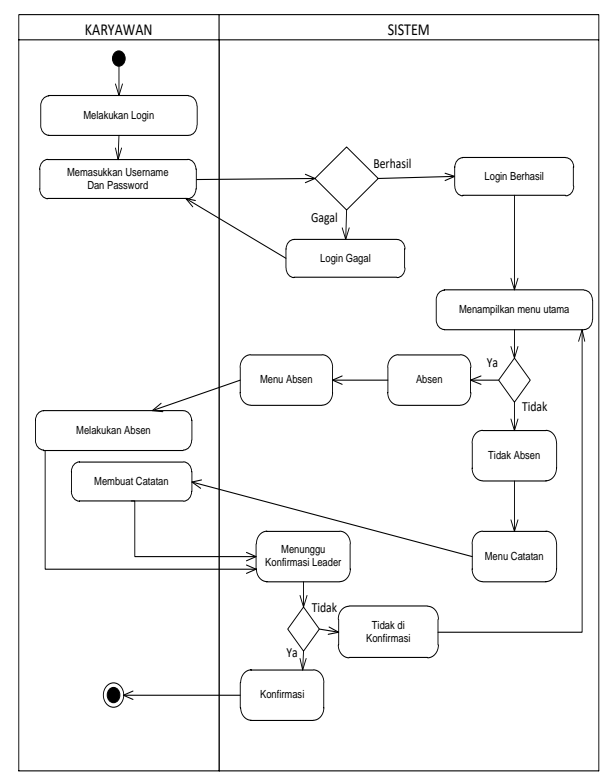

Gambar 5. Activity Diagram Karyawan

- Activity Diagram Leader

Dalam menjelaskan aktivitas karyawan didalam sistem absensi dapat dilihat dalam gambar 6 Activity Diagram Leader

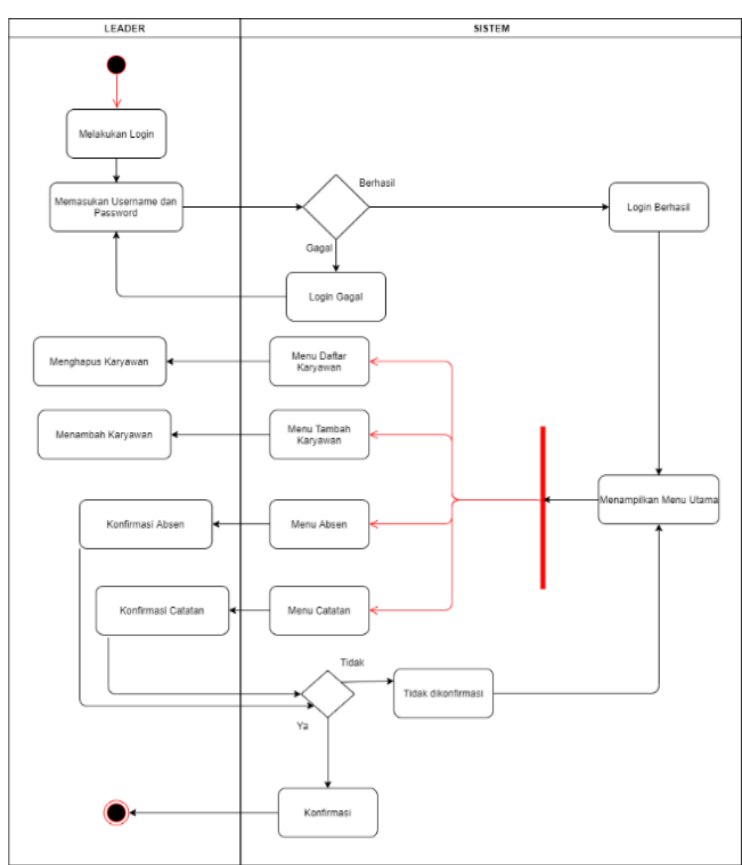

Gambar 6. Activity Diagram Leader

- Class Diagram

Dalam menjelaskan class dan operasi yang ada didalam sistem absensi dapat dilihat dalam gambar 7

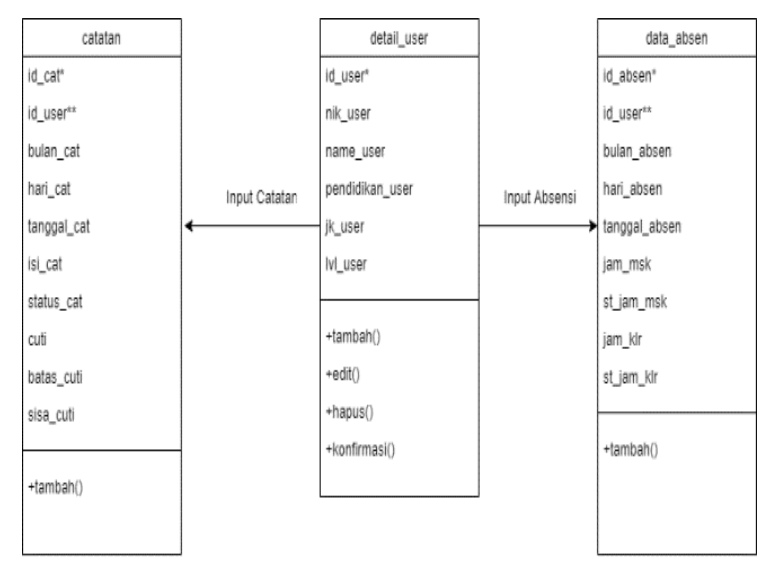

Gambar 7. Class Diagram

1.

2.

3.

4. 
- Entity Relationship Diagram (ERD)

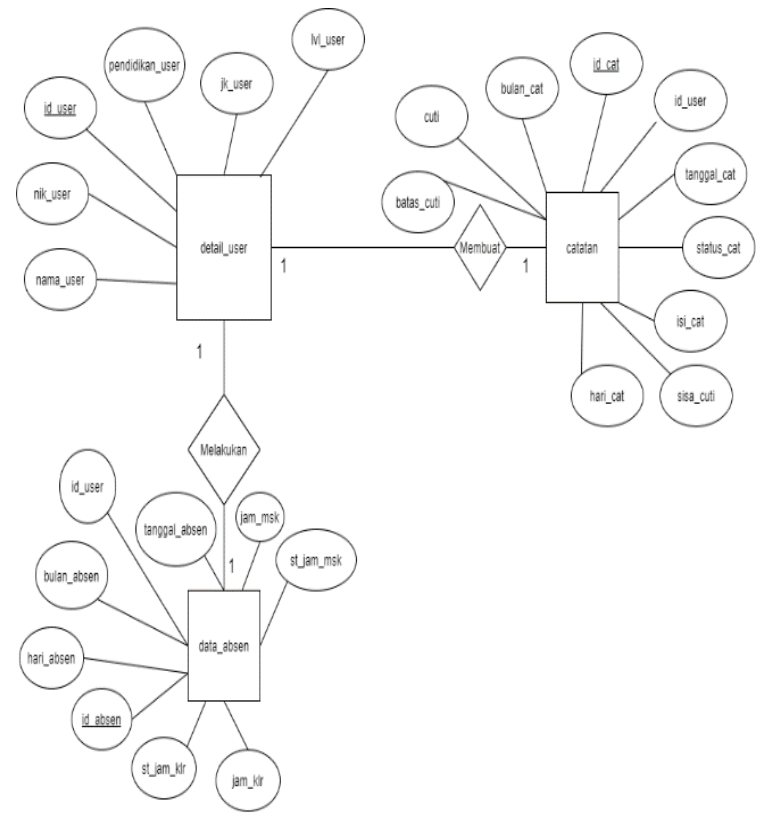

Gambar 8. Entity Relationship Diagram (ERD)

\section{c. Desain User Interface}

Berisikan implementasi hasil rancangan user interface yang dibuat tentang sistem informasi monitoring absensi karyawan berbasis web.

\section{- Menu Login Akses Leader/Karyawan}

Menu login dimaksudkan untuk login leader maupun karyawan dan kegunaanya sebagai akses untuk membuka halaman berdasarkan level akses. Jika yang melakukan login Username dengan level akses karyawan, maka akan diarahkan ke karyawan. Jika yang melakukan login Username dengan level akses leader, maka akan diarahkan ke leader.

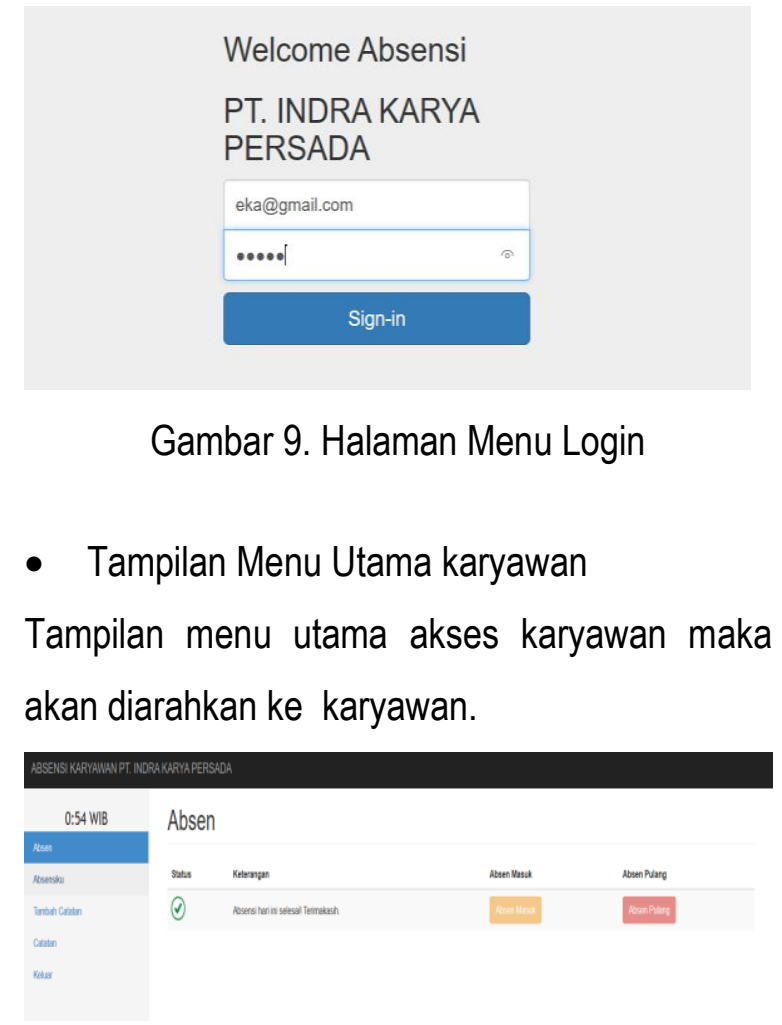

Gambar 10. Tampilan Menu Utama Karyawan

- Tampilan Menu Data Absensi Karyawan

Melihat data absensi karyawan yang telah dilakukan.

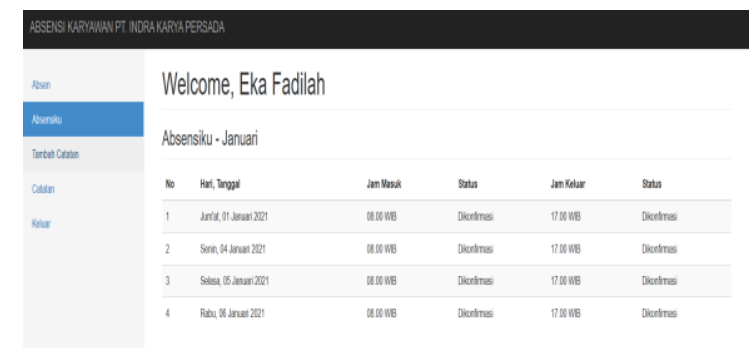

Gambar 11. Tampilan Menu Data Absensi Karyawan

- Tampilan Menu Tambah Catatan

Karyawan dapat juga fitur untuk membuat laporan dengan tujuan memberitahu pekerjaan, lembur atau izin ke leader. 


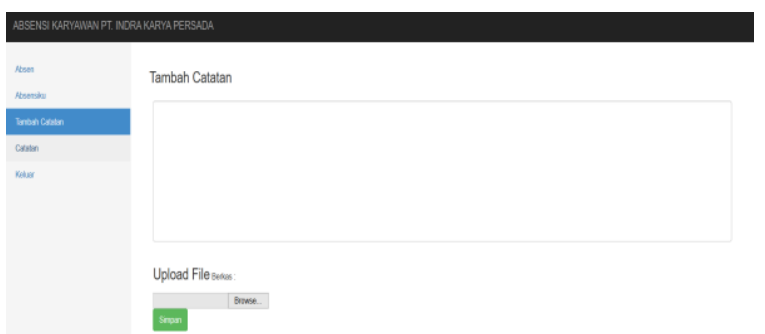

Menu ini perlu di perhatikan oleh leader agar termonitor dikarenakan setiap user karyawan yang membuat laporan pekerjaannya, maka leader harus konfirmasi atau pun tolak sesuai dengan keadaan.

\section{Gambar 1. Tampilan Menu Tambah Catatan}

- Tampilan Menu Data Catatan Karyawan

pada menu ini, setelah catatan di konfirmasi oleh leader, maka karyawan dapat mengetahui status catatan pada absensinya.

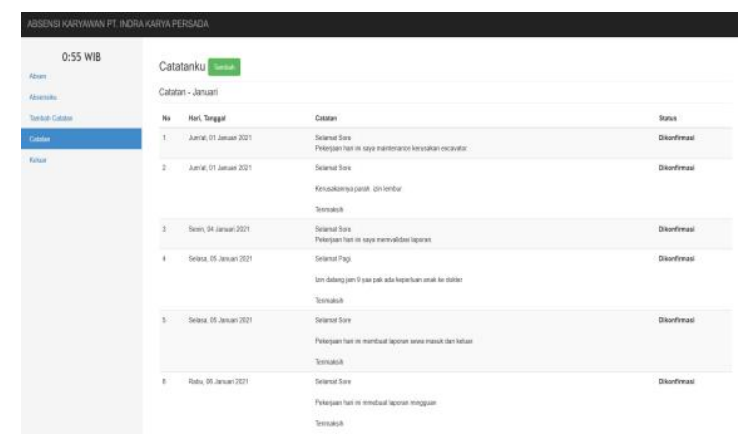

Gambar 2. Tampilan Menu Data Catatan

\section{Karyawan}

\section{- Menu Daftar Karyawan}

Setalah leader mendaftarkan karyawan, maka data nya bisa di lihat di menu ini informasi semua karyawan yang masih aktif. Di menu ini leader dapat edit dan hapus karyawan.

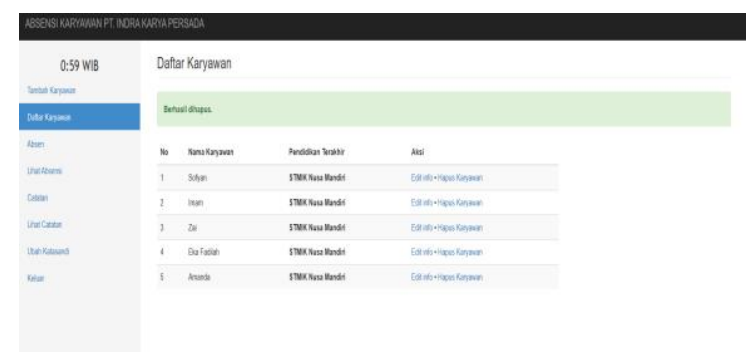

Gambar 3. Halaman Menu Daftar Karyawan

- Menu Konfirmasi Catatan Karyawan

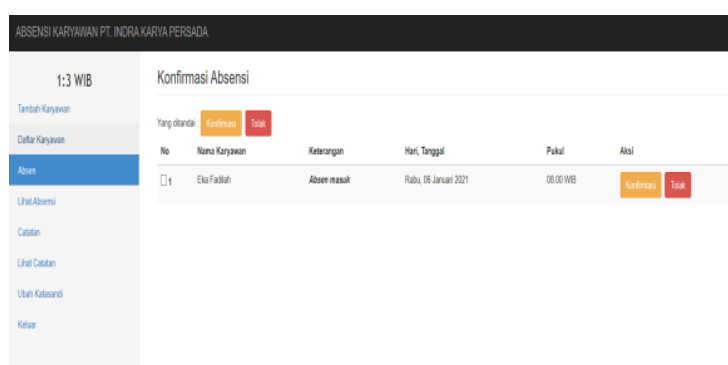

Gambar 4. Halaman Menu Konfirmasi Absensi Karyawan

- Menu Konfirmasi Absensi Karyawan

Menu ini perlu di perhatikan oleh leader dikarenakan setiap user karyawan yang absen masuk dan keluar, maka leader harus konfirmasi atau pun tolak sesuai dengan keadaan.

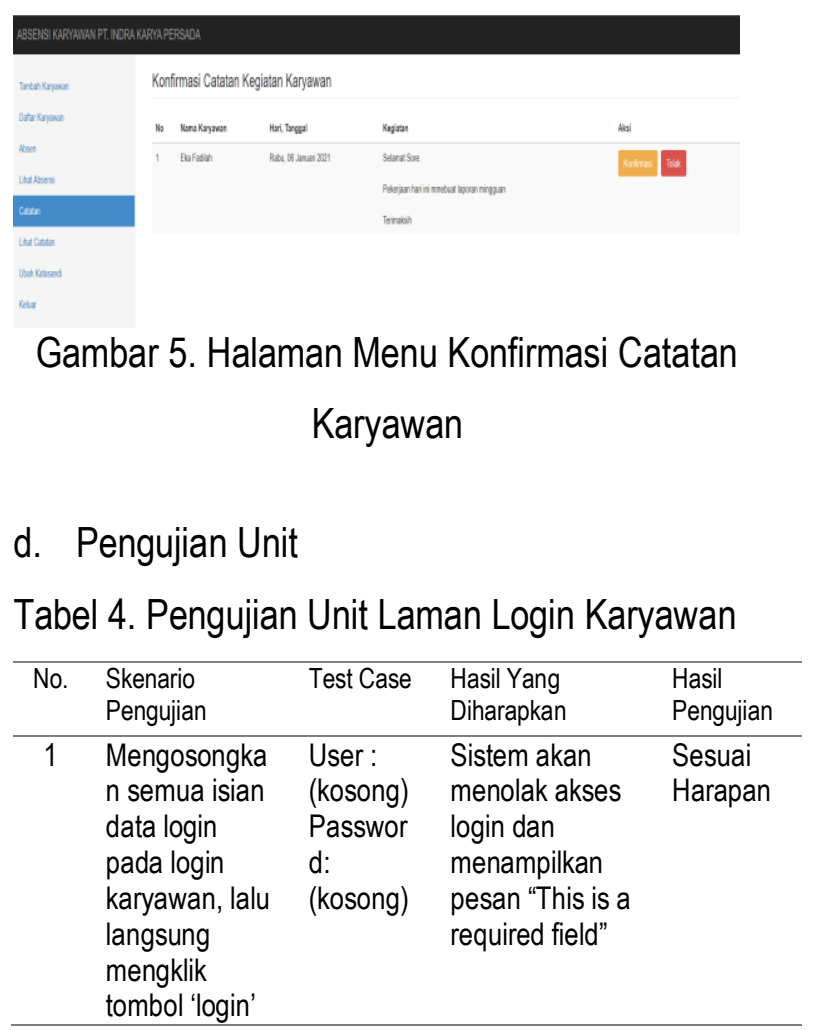


Link : https://dx.doi.org/10.29408/jit.v4i2.3721

\begin{tabular}{|c|c|c|c|c|}
\hline 2 & $\begin{array}{l}\text { Hanya } \\
\text { mengisi data } \\
\text { Email dan } \\
\text { mengosongka } \\
\text { n data } \\
\text { password, lalu } \\
\text { langsung } \\
\text { mengklik } \\
\text { tombol'login' }\end{array}$ & $\begin{array}{l}\text { User: } \\
\text { (sofyan } \\
\text { @gmail. } \\
\text { com) } \\
\text { Passwor } \\
\text { d: } \\
\text { (kosong) }\end{array}$ & $\begin{array}{l}\text { Sistem akan } \\
\text { menolak akses } \\
\text { login dan } \\
\text { menampilkan } \\
\text { pesan "This is a } \\
\text { required field" }\end{array}$ & $\begin{array}{l}\text { Sesuai } \\
\text { Harapan }\end{array}$ \\
\hline 3 & $\begin{array}{l}\text { Hanya } \\
\text { mengisi data } \\
\text { password } \\
\text { dan } \\
\text { mengosongka } \\
\text { n data email, } \\
\text { lalu langsung } \\
\text { mengklik } \\
\text { tombol'login }\end{array}$ & $\begin{array}{l}\text { User: } \\
\text { (kosong) } \\
\text { Passwor } \\
d: \\
(1234)\end{array}$ & $\begin{array}{l}\text { Sistem akan } \\
\text { menolak akses } \\
\text { login dan } \\
\text { menampilkan } \\
\text { pesan "This is a } \\
\text { required field" }\end{array}$ & $\begin{array}{l}\text { Sesuai } \\
\text { harapan }\end{array}$ \\
\hline 4 & $\begin{array}{l}\text { Menginputkan } \\
\text { dengan } \\
\text { kondisi salah } \\
\text { satu data } \\
\text { benar dan } \\
\text { satu lagi } \\
\text { salah, lalu } \\
\text { langsung } \\
\text { mengklik } \\
\text { tombol 'login' }\end{array}$ & $\begin{array}{l}\text { User: } \\
\text { sofyan@ } \\
\text { gmail.co } \\
\text { m(benar) } \\
\text { Passwor } \\
\text { d: } \\
123456 \\
\text { (salah) }\end{array}$ & $\begin{array}{l}\text { Sistem akan } \\
\text { menolak akses } \\
\text { login dan } \\
\text { menampilkan } \\
\text { pesan "Periksa } \\
\text { kembali email \& } \\
\text { katasandi } \\
\text { Anda!" }\end{array}$ & $\begin{array}{l}\text { Sesuai } \\
\text { harapan }\end{array}$ \\
\hline 5 & $\begin{array}{l}\text { Menginputkan } \\
\text { data login } \\
\text { yang benar, } \\
\text { lalu mengklik } \\
\text { tombol 'login' }\end{array}$ & $\begin{array}{l}\text { user: } \\
\text { sofyan@ } \\
\text { gmail.co } \\
\text { m } \\
\text { Passwor } \\
\text { d: } 12345\end{array}$ & $\begin{array}{l}\text { Sistem } \\
\text { menerima } \\
\text { akses login dan } \\
\text { kemudian } \\
\text { langsung } \\
\text { menampilkan } \\
\text { beranda } \\
\text { absensi dan } \\
\text { laporan }\end{array}$ & $\begin{array}{l}\text { Sesuai } \\
\text { harapan }\end{array}$ \\
\hline
\end{tabular}

\section{Kesimpulan}

Berdasarkan pembuatan sistem informasi monitoring absensi pada PT Indra Karya Persada ini, maka dapat disimpulkan yakni sistem informasi tersebut memudahkan leader untuk melakukan memonitor absen, merekap data absen dan laporan kegiatan karyawan. Dan dengan memanfaatkan web menjadikan sistem ini dapat diakses dimanapun dengan koneksi internet, sehingga karyawan yang bertugas dilapangan tidak perlu lagi datang ke kantor untuk melakukan absensi. Pengembangan sistem informasi kedepannya dapat ditambahkan fitur-fitur yang belum terdapat dalam dalam website saat ini.

\section{Daftar Pustaka}

[1] C. Carso, Y. Purwati, S. Gustin and A. P. Kuncoro, "Rancang Bangun Aplikasi Pengaduan Pelanggan Berbasis Web Menggunakan Framework Codeigniter Di Indotechno Purwokerto," Jurnal Sains dan Informatika, vol. 6, pp. 166-174, 2020.

[2] T. Triyono, R. Safitri, and T. Gunawan, "Perancangan Sistem Informasi Absensi Guru Dan Staff Pada Smk Pancakarya Tangerang Berbasis Web," SENSI J., 2018.

[3] S. Suhartini, M. Sadali and Y. K. Putra, "Sistem Informasi Berbasis Web Sma AlMukhtariyah Mamben Lauk Berbasis Php Dan Mysql Dengan Framework Codeigniter," Infotek : Jurnal Informatika dan Teknologi, vol. 1, pp. 79-83, 2020.

[4] M. Danny and S. R. Permadi, "Implementasi Sistem Monitoring Absensi Berbasis Rfid Proxymity," SIGMA - Jurnal Teknologi Pelita Bangsa, pp. 47-53, 2020.

[5] S. Subiantoro and S. Sardiarinto, "Perancangan Sistem Absensi Pegawai Berbasis Web Studi Kasus: Kantor Kecamatan Purwodadi," Swabumi, 2018.

[6] N. Afni, R. Pakpahan and A. R. Jumarah, "Rancang Bangun Sistem Informasi Penggajian Dengan Implementasi Metode Waterfall," Jurnal Khatulistiwa Informatika, vol. VII, pp. 99-104, 2019.

[7] Wihana, V. O., and Amrullah, F. (2019). "Penerapan Sistem Informasi Presensi Mahasiswa Menggunakan Fingerprint Berbasis Web." Journal of Computer Science and Applied Informatics.

[8] Wijaya, A. (2020). "Evaluasi Sistem Dashboard Monitoring Presensi Akademik 
Mahasiswa." JARTIKA Jurnal Riset Teknologi Dan Inovasi Pendidikan.

[9] F. Andalia and E. B. Setiawan, "Pengembangan Sistem Informasi Pengolahan Data Pencari Kerja Pada Dinas Sosial Dan Tenaga Kerja Kota Padang," Komputa J. IIm. Komput. dan Inform., 2015.

[10] N. Rio, D. Hariyanto and E. Sunita, "Rancang Bangun Sistem Informasi Absensi Karyawan Pada PT. San Andreas Mandiri Bekasi," IJSE - Indonesian Journal on Software Engineering, vol. 5, pp. 34-41, 2019.

[11] G. Farell, H. Saputra, and I. Novid, "Rancang Bangun Sistem Informasi Pengarsipan Surat Menyurat (Studi Kasus Fakultas Teknik Unp)", tip, vol. 11, no. 2, pp. 55-62, Sep. 2018.

[12] S. Sidik, A. Maulana and B. A. Wahid, "Penerapan Model Waterfall Pada Sistem Informasi Penjualan Berbasis Web," Jurnal Format, vol. 9, pp. 48-57, 2020.

[13] H. Ahmadi and M. H. Nasution, "Rancang Bangun System Komputerisasi Penguatan Pelayanan Kelompok Penyelenggara Sanitasi Penyedia Air Minum (KPSPAM "DJ-Menteng") Desa Pendem Kec. Janapria," Infotek : Jurnal Informatika dan Teknologi, vol. 2, pp. 119-126, 2019.

[14] M. A. R. Sikumbang, R. Habibi and S. F. Pane, "Sistem Informasi Absensi Pegawai Menggunakan Metode RAD dan Metode LBS Pada Koordinat Absensi," Jurnal Media Informatika Budidarma, vol. 4, no. 1, pp. 59-64, 2020.

[15] A. Simangunsong, "Sistem Informasi Pengarsipan Dokumen Berbasis Web", J.Mantik Penusa, Mantik Penusa, vol. 2, no. 1, Apr. 2018.
[16] A. Sudianto and H. Ahmadi, "Rancang Bangun Sistem Informasi Penjualan Sparepart Motor Pada Bengkel Vinensi Motor Berbasis Web Guna Meningkatkan Penjualan dan Promosi Produk Pendahuluan Vinensi sepeda motor motor," Infotek J. Inform. dan Teknol., vol. 3, no. 2, pp. 32-39, 2020. 